E genero Psilotum se ubica en la familia Psilotaceae, División Psilotophyta. Incluye dos especies distribuidas en América, África, Australia y Asia. Ambas especies ( $P$. complanatum y $P$. triquetum ( $P$. nudum)) se encuentran presentes en México. Los miembros de este género han sido considerados como las plantas vasculares más primitivas que habitan en nuestro planeta, presentando la organización menos compleja de una División que comprende tan solo dos géneros. Como todas las plantas vasculares Psilotum presenta alternancia de generaciones con el esporofito como la fase dominante. Sus ejes o tallos son aplanados y ramificados dicotómicamente y tiene rizomas subterráneos, que carecen de raíces. Estas plantas no presentan hojas sino solamente pequeñas escamas, sin tejido vascular (profilos); los esporóforos sostienen sobre el tallo estructuras llamadas sinangios en cuyo interior se producen las esporas. El gametofito es cilíndrico, subterráneo, saprofítico y presenta una asociación micorrícica, por lo que es aclorofílico (Bierhorst, 1992; Foster y Gifford, 1974).

En México, las especies de Psilotum han sido recolectadas desde sitios ubicados al norte del país como el Cañón de Nacapule en Guaymas, Sonora, hasta regiones más sureñas como la Selva Lacandona. Esta distribución, relativamente amplia, indica que estas especies pueden prosperar en sitios con condiciones macroecológicas muy diversas, que abarcan amplios intervalos altitudinales y varios tipos de vegetación como el bosque tropical subcaducifolio, el bosque mesófilo,y los manglares.

Para el Pedregal de San Ángel, y específicamente dentro del área que actualmente ocupa el Jardín Botánico de la UNAM, Rzedowski en 1954 reportó una pequeña población de plantas de este género a la que identificó como $P$. triquetum $\mathrm{Sw}$.

\title{
Psilotum complanatum Sw. en el Pedregal de San Ángel
}

\section{Carlos Galindo Rosete y Leonel López Toledo}

Facultad de Ciencias, Universidad Nacional Autónoma de México, Apartado postal 70-356, Coyoacán, 04510 México, D. F., México.

(que estaba mal determinado). Los ejemplares de respaldo de este registro fueron depositados en el Herbario ENCB, donde recientemente fueron identificados como $P$. complanatum por M.L. Arreguín. En estudios recientes se había mencionado la posibilidad de que esta especie hubiera desaparecido del área del Pedregal de San Ángel (Panti Madero, 1984), zona sobre la que actualmente existe una fuerte presión de urbanización. La población de $P$. complanatum fue encontrada en una pequeña área ubicada dentro de Ciudad Universitaria, en la Delegación Coyoacán, Distrito Federal, aunque fuera de los límites de la zona decretada como Reserva Ecológica. Consta de 14 individuos, que crecen en una grieta con suelo escaso, ubicada en una falla de roca ígnea en la cual desafortunadamente se ha acumulado una gran cantidad de basura. Los individuos presentan tallos profusamente dicotomizados, nueve de ellos miden entre 26 y $30 \mathrm{~cm}$ de largo y el resto son más pequeños, pues sólo alcanzan de 8 a $10 \mathrm{~cm}$ de longitud. Los primeros son evidentemente individuos adultos pues presentan sinangios maduros y dehiscentes, mientras los más pequeños tienen sinangios inmaduros y aún cerrados. Los sinangios en ambos casos presentan una disposi- ción en pares subopuestos o alternos sobre los márgenes de los tallos, y sostenidos sobre los esporófilos que son bifurcados. Los tallos miden aproximadamente $3 \mathrm{~mm}$ de ancho en su porción aplanada, y de acuerdo con las claves analíticas correspondientes los ejemmplares fueron determinados como $P$. complanatum (Palacios-Ríos, 1995; Mickel y Beitel, 1988). Esta determinación fue corroborada por Ramón Riba.

Aunque las especies de Psilotum son de amplia distribución, las poblaciones son escasas y con pocos individuos, lo que tal vez es debido al largo tiempo que necesitan para la germinación de esporas (un año en condiciones de laboratorio), además de que es una planta micorrícica que requiere de condiciones muy particulares para la formación de su ciclo de vida. Generalmente tales condiciones se encuentran en comunidades vegetales no alteradas, principalmente en el bosque mesófilo de montaña. Sin embargo, este tipo de vegetación, está actualmente sometido a altas tasas de tala y desmonte, por lo que estos organismos al igual que otros, son altamente vulnerables. Debido a estas razones y principalmente al crecimiento urbano se ha considerado a las especies de Psilotum como plantas en peligro de extinción ((Palacios-Ríos, 1987). Por esto, consideramos que 
el redescubrimiento de una pequeña población en un área tan urbanizada es importante en términos de la biodiversidad del Pedregal de San Ángel.

\section{Literatura citada}

Bierhorst D. 1972. Morphology of Vascular Plants. Mac Millan. New York. 98-105.

Foster A.S. y Gifford E.M. 1974. Comparative Morphology of Vascular Plants. W.H. Freeman y Co. San Francisco. 117-133.
Mickel J.T. y Beitel J. 1988. Pteridophyte Flora of Oaxaca, Mexico. Memories of the New York Botanical Garden. 46:1-3

Palacios-Ríos M. 1987. Flora de Veracruz. Psiloteaceae. INIREB, Xalapa.

Palacios-Ríos M. 1995. Psilotaceae. En: Davidse G., Sousa M. y Knapp S. Edrs. Flora Mesoamericana Vol. 1 Psilotaceae a Salviniaceae. Universidad Nacional Autónoma de México, Missouri Botanical Garden y The Natural History Museum (London), México, D.F. 34.
Panti Madero M.A. 1984. Contribución al conocimiento del Pedregal de San Ángel sobre el problema de su flora y conservación. Tesis de Licenciatura, Facultad de Ciencias, Universidad Nacional Autónoma de México. México, D.F.

Rzedowski J. 1954 Vegetación del Pedregal de San Ángel, Distrito Federal, México. Anales de la Escuela Nacional de Ciencias Biológicas, Instituto Politécnico Nacional. 8(1-2):59-129 